\title{
Procedure Duration of Procedure
}

National Cancer Institute

\section{Source}

National Cancer Institute. Procedure Duration of Procedure. NCI Thesaurus. Code C117533.

The period of time from start to finish of the procedure. 